\title{
CONTRIBUIÇÃO AO CONHECIMENTO DAS ALTERAÇÕES NEUROLÓGICAS EM PACIENTES COM SIDA
}

\author{
VILMA DULARTE CÂMARA *, WALTER TAVARES**, MARCY PEREIRA RIBEIRO DA ROCHA ** , \\ LEILA CARDÄO CHIMELUI***, MYRIAM DUMAS-HAHN****
}

RESUMO - Nesta pesquisa fizemos estudo retrospectivo de 154 pacientes com SIDA, submetidos a necropsia no Hospital Universitário Antonio Pedro da Universidade Federal Fluminense $e$ cujos resultados mostraram lesőes do sistema nervoso. Destacamos, da casuística, dados epidemiológicos, clínicos e anátomo-patológicos, de tempo de evoluçăo e de correlaçăo anátomo-clínica. Objetivamos, com este estudo, contribuir na definiçẵo da importância do acometimento neurológico no diagnóstico precoce da síndrome de imunodeficencia adquirida.

PALAVRAS-CHAVE: SIDA (AIDS), diagnóstico precoce, manifestaçðes neurológicas.

Contribution to knowledge of neurological findings in AIDS patients

SUMMARY - We performed a retrospective study of 154 patients with AIDS that presented lesions of the nervous system at necroscopic examination. Necropsies were performed in the Hospital Universitario Antonio Pedro (Niteroi, Brazil). We emphasize epidemiologic and clinical data, neuropathologic findings, evolution time, and anatomo-clinical correlation. Data obtained can contribute in the definition of consequences of neurologic symptoms and signs for early diagnosis and best prognosis in AIDS.

KEY WORDS: AIDS, early diagnosis, neurologic manifestations.

Nosso interesse pelo tema se deve ao fato de ser grande a demanda de pacientes HIV + para o Hospital Universitário Antonio Pedro da Universidade Federal Fluminense, por ser hospital de referência para SIDA, o único na regiāo, com leitos no Serviço de Doenças Infecto-Parasitárias (DIP), e nas demais enfermarias, com atividade de hospital-dia, com ambulatórios de DIP, Clínica Médica e Neuro-SIDA. Temos observado manifestaçð̌es neurológicas como quadro inicial em pacientes de ambulatório e internados e, também, como causa de morte desses pacientes.

A casuística aqui estudada permite correlacionar as manifestaçððes clínicas neurológicas e os achados anátomo-patológicos, o que contribui para facilitar o diagnóstico e intervençăo precoce no tratamento, evitando a evolução rápida para o óbito após a instalação do quadro neurológico.

\section{MATERIAL E METTODOS}

Foram revistos 154 pacientes com SIDA que evoluíram para o obito no periodo de setembro-1984 a dezembro-1990, os quais foram submetidos a necropsia no Departamento de Patologia do HUAP. Do total de 154 pacientes, apenas três não tinham apresentado sintomatologia neurologica, embora tivessem lesð̄es neuropatológicas.

Trabalho realizado no Hospital Universitário Antonio Pedro (HUAP) da Universidade Federal Fluminense (UFF): *Professor Adjunto de Neurologia, UFF; **Professor Titular de Doenças Infecto Parasitárias, UFF; ***Mestranda em Neurologia, UFF; ****Professor Adjunto de Neuropatologia, UFF. Aceite: 5-agosto-1994. 
Tabela I. Manifestaçōes neurológicas em pacientes com SIDA em 154 casos necropsiados.

\begin{tabular}{lcc}
\hline Sinais e sintomas neurologicos & Casos & \% \\
\hline \hline Alteraçóes mentais & 65 & 42,2 \\
Coma & 63 & 40,9 \\
Cefaléia & 53 & 34,4 \\
Síndrome meningea & 48 & 31,2 \\
Déficit motor & 37 & 24,0 \\
Crise convulsiva & 25 & 16,2 \\
Neuropatia periférica & 21 & 13,6 \\
Deméncia & 9 & 5,8 \\
Neuropatia de nervo craniano & 4 & 2,6 \\
Síndrome medular & 3 & 1,9 \\
Sem sinais neurologicos & 3 & 1,9 \\
Ataxia & 2 & 1,2 \\
Polirradiculopatia & 1 & 0,6 \\
Coreoatetose & 1 & 0,6 \\
\hline
\end{tabular}

Obs.: Os pacientes apresentaram multiplicidade de sinais e sintomas neurológicos.

Os pacientes foram submetidos a exames clínico, neurológico e complementares (como: testes sorológicos, rotina de sangue, tomografia cerebral computadorizada, eletrencefalograma e velocidade de conduçăo nervosa.

Quanto ao exame neuropatológico, os cérebros foram fixados em formol a $20 \%$, no mínimo durante 2 semanas e depois submetidos a cortes coronais com retirada de fragmentos de todas as regióes. Os métodos de coloraça utilizados foram: hematoxilina e eosina, PAS, Grocott, Ziehl-Neelsen, luxol fast blue. Reaçбes imunohistoquímicas foram usadas em um s6 caso.

Do total dos pacientes, $136(88,3 \%)$ eram homens e $18(11,7 \%)$ mulheres. Na avaliação quanto ao comportamento de risco, a transmissäo sexual foi a de maior frequência: 95 casos (61\%), que ficaram distribufdos em 52 homossexuais $(33,8 \%), 18$ bissexuais $(11,7 \%), 15$ homo/droga $(9,7 \%), 5$ promíscuos $(3,2 \%), 4$ heterossexuais $(2,6 \%)$ e 1 bissexualdroga $(0,6 \%)$. Nos demais casos, foi: em 21 por transfusão sanguínea, incluindo hemofilicos; em 5 por drogas injetáveis; em 33, de transmissão ignorada. Destes, 6 eram mulheres e 27. homens. Na transmissăo por transfusæă, 13 pacientes eram do sexo masculino e 8 do feminino. Quanto ao estado civil, verificou-se que 40 eram solteiros $(64,5 \%), 20$ (32,3\%) casados e 2 separados (3,2\%). Na distribuiçăo por idade, ocorreu predominância de pacientes entre 30-39 anos, com 4 casos $(2,6 \%)$ do sexo feminino e 55 (33.71\%) do masculino. As faixas etárias seguintes foram: 40-49 anos com $37(24,03 \%)$ homens e $4(2,6 \%)$ mulheres; de 20-29 anos com 33 homens $(21,4 \%)$ e $8(5,19 \%)$ mulheres. A frequência em idade acima de 49 anos foi de 11 pacientes $(7,14 \%)$ do sexo masculino e $2(1,3 \%)$ do feminino. A média de idade foi 36,4 anos.

\section{RESULTADOS}

Dados clínicos - As manifestaçóes neurológicas encontradas nos pacientes foram: alteraçð̃es mentais, síndrome meníngea, cefaleia, crise convulsiva, déficit motor, demência, coma, síndrome de nervo periférico, síndrome medular (por mielopatia vacuolar), polirradiculomielite, ataxia, coreoatetose e alteraçōes de nervos cranianos. Em 3 pacientes năo ocorreram sintomas neurológicos (Tabela 1).

A observação da frequência mostra que alterą̧ðes mentais ocorreram em 65 pacientes $(42,2 \%)$ por ação de agentes oportunistas como Toxoplasma gondii. Cryptococcus neoformans e citomegalovirus e 9 por açăo do próprio virus da imunodeficiência humana (demência). Um paciente apresentava lesāo cerebral pela ação do próprio virus, mas faleceu antes de apresentar alteracōes mentais. Incluimos como alterações mentais os distúrbios da memória, desorientaçăo, confusāo mental, apatia e distúrbios do comportamento. Ainda, encontramos alteraçes mentais em: 11 pacientes que apresentaram associaçăo de vários agentes etiológicos; 2 , cujo achado anśtomo-patologico foi normal; 2 , com alteraçoes inespecíficas.

As sindromes meníngeas eram caracterizadas por cefaleia e rigidez de nuca $(31,2 \%)$ : a cefaleia surgiu em frequencia marcante devido a ocorrencia de síndrome meníngea e à presença de lesðes cerebrais pelos diversos agentes oportunistas. As crises convulsivas foram generalizadas; somente em um caso a crise era 
Tabela 2. Tempo de evolução. Tempo TI: tempo entre manifestações clínicas da SIDA e os sintomas neurologicos. Tempo T2: tempo entre quadro neurológico e o óbito.

\begin{tabular}{lcccc}
\hline \multirow{2}{*}{ TEMPO } & \multicolumn{2}{c}{ T1 } & \multicolumn{2}{c}{ T2 } \\
\cline { 2 - 5 } & $N^{0}$ de casos & $\%$ & $N^{\circ}$ de casos & $\%$ \\
\hline \hline$/--2$ meses & 42 & 27,3 & 129 & 83,8 \\
$2 /---4$ meses & 37 & 24,0 & 13 & 8,4 \\
$4 /--7$ meses & 19 & 12,3 & 4 & 2,5 \\
$7 /---8$ meses & 2 & 1,3 & - & - \\
8 meses & 14 & 9,1 & 148 & 96,3 \\
Total parcial & 114 & 74,0 & 6 & 3,8 \\
Ignorado & 40 & 26,0 & 154 & 100 \\
Total & 154 & 100 & & 2 \\
\hline
\end{tabular}

dimidiada. Deficit motor ocorreu em 37 pacientes; hemiplegia ou hemiparesia em 22, paraparesia/paraplegia em 2 e monoparesia em 1 foram encontrados em pacientes com toxoplasmose cerebral. A evoluçăo clínica mais frequente foi para o coma, observado em 63 pacientes $(40,9 \%)$ e causado por lesōes cerebrais, distúrbios metabólicos e distúrbios cardio-respiratórios.

Devido à grande variabilidade na evolução e ao prognóstico, muito reservado a partir do início das manifestaçð̄es neurológicas, estabelecemos dois tempos de evoluçăo, em meses e dias: - tempo T1, em meses e dias entre o início dos sintomas sistêmicos da SIDA e o início do quadro neurológico; - tempo T2, entre estas complicações e o óbito (Tabela 2). Considerando os tempos T1 e T2, fizemos a associaçăo entre o surgimento das manifestaçð̃es neurológicas e o tempo de evolução (Tabela 3). Destacamos nestes resultados a importância do tempo de início e do tempo de evolução das manifestaçбes neurologicas em pacientes com SID́A. Observamos que, em grande número de pacientes (36,8\% dos 114 em que apuramos o tempo de início), o surgimento das alterações neurológicas ocorreu com 1 mês ou menos do início das manifestaçøes sistêmicas e que, na maioria dos casos (68,3\%), o comprometimento neurologico ocorreu antes dos 4 meses de SIDA.

Por outro lado, a evolução para o óbito (tempo T2) foi também rápida, mostrando a gravidade e o man prognóstico quando ocorre quadro neurológico na SIDA. Como exemplo, em 87,2\% dos casos, este tempo foi de menos de 4 meses.

Tabela 3. Associação entre Tl e T2 e manifestaçzes neurológicas.

\begin{tabular}{lcccccccccc}
\hline & \multicolumn{4}{c}{ T1 em meses } & \multicolumn{5}{c}{ T2 em meses } \\
\cline { 2 - 11 } Sinais e sintomas & 2 & 2 a 4 & 4 a 7 & 7 e 8 & 8 & 2 & 2 a 4 & 4 a 7 & 7 e 8 & 8 \\
\hline \hline Alterações mentais & 34 & 12 & 11 & 1 & 7 & 56 & 8 & - & - & 1 \\
Síndrome meníngea & 21 & 11 & 9 & 1 & 6 & 39 & 5 & 3 & - & 1 \\
Cefaléia & 27 & 18 & 5 & - & 3 & 46 & 3 & 3 & - & 1 \\
Convulsão & 10 & 5 & 4 & 1 & 5 & 22 & 1 & 1 & - & 1 \\
Défícit motor & 22 & 4 & 3 & 2 & - & 32 & 2 & 1 & - & 2 \\
Demência & 4 & 1 & - & - & - & 6 & 2 & 1 & - & - \\
Coma & 40 & 11 & 8 & 1 & 3 & 57 & 3 & 1 & - & 2 \\
Neuropatia periférica & 8 & 7 & 4 & - & 2 & 16 & 5 & - & - & - \\
Síndrome medular & 1 & - & 1 & - & 1 & 1 & 1 & 1 & - & - \\
Polirradiculomielite & - & 1 & - & - & - & 1 & - & - & - & - \\
Sem sintomas neurológicos & 3 & - & - & - & - & 3 & - & - & - & - \\
Ataxia & 1 & - & - & 1 & - & 1 & - & - & - & 1 \\
Coreoatetose & - & - & - & - & 1 & - & - & 1 & - & - \\
Neuropatia craniana & 3 & 1 & - & - & - & 4 & - & - & - & - \\
\hline
\end{tabular}


Tabela 4. Achados etiológicos no SNC de 154 pacientes infectados pelo HIV.

\begin{tabular}{|c|c|c|}
\hline Achados etiologicos & Frequencia & $\boldsymbol{\psi}$ \\
\hline \multicolumn{2}{|l|}{ 1. Infeçros oportunistas } & \\
\hline $\begin{array}{l}\text { Toxoplasmose } \\
\text { - Fungos }\end{array}$ & 60 & 38,9 \\
\hline Criptococose & 24 & 24,9 \\
\hline . Histoplasmose & 1 & \\
\hline \multicolumn{3}{|l|}{ - Bactérias } \\
\hline Meningite tuberculosa (Mycobacterium) & 2 & 1,6 \\
\hline $\begin{array}{l}\text {. Meningite bacteriana } \\
\text { - Virus }\end{array}$ & 1 & 0,8 \\
\hline Citomegalovirose & 14 & \\
\hline Leucoencefalopatia multifocal progressiva & 2 & 22,8 \\
\hline Encefalite nodular & 10 & \\
\hline \multicolumn{3}{|l|}{ 2. Neoplasias } \\
\hline . Linfoma & 5 & 3,2 \\
\hline \multicolumn{3}{|l|}{ 3. Lesōes induzidas pelo HIV } \\
\hline . Encefalite pelo HIV & 10 & 6,4 \\
\hline . Mielopatia vacuolar & 3 & 1,9 \\
\hline . Meningite de base & 2 & 1,2 \\
\hline \multicolumn{3}{|l|}{ 4. Lesoes vasculares } \\
\hline Infarto e hemorragia & 9 & 5,8 \\
\hline 5. Lesós inespecificas & 20 & 12,9 \\
\hline 6. Sem lesס̌es (Normal) & 9 & 5,8 \\
\hline
\end{tabular}

Obs.: (1) Năo foi feito exame anatomo-patológico em medula espinhal; o diagnóstico de mielopatia vacuolar so foi clínico, associado a linfoma, criptococose e citomegalovirose. (2) Este resultado se deve ao fato de 16 pacientes apresentarem múltiplas lesões do SNC.

Revendo os sinais e sintomas neurologicos no tempo $\mathrm{T} 1$, observa-se que o comprometimento neurológico na SIDA manifestou-se precocemente como: coma, alteraçðes mentais, cefaléia, déficit motor e síndrome meníngea. Estas mesmas manifestaçōes, acrescidas do quadro de convulsão, são indicativas de gravidade do quadro clínico, estando presentes predominantemente nos pacientes que evolufram para o óbito dentro de 1 mês ou menos do inf́cio das manifestaçőes neurológicas.

Em nossa casurstica a evoluça para o óbito em 6 meses ocorreu em $98,6 \%$ dos casos.

O tempo de sobrevida depende do diagnóstico e da terapêutica precoce, especialmente quando as manifestaçóes neurológicas stâo decorrentes de infecçōes oportunistas como toxoplasmose, criptococose e citomegalovirose. Consequentemente, a evoluçăo da infeç̧ăo é, muitas vezes, depedente da habilidade e conhecimento medico e dos recursos disponfveis para o estabelecimento do diagnóstico e terapêutica.

Dados anátomo-patológicos - A presente série de 154 casos mostrou $145(94,1 \%)$ com achados anátomopatologicos de lesð́es no sistema nervoso central (SNC). Este dado fortalece a alta frequência do envolvimento deste sistema nos pacientes com SIDA. Encontramos 16 casos $(10,3 \%)$ com infecções múltiplas e/ou tumores e $9(5,8 \%)$ sem lesð̄es anátomo-patológicas. Oconreram 114 infecçőes oportunistas (74\%), incluindo 60 por protozoários (38,9\%), 26 por vírus $(22,8 \%), 25$ por fungos $(24,9 \%), 1$ por bactérias $(0,8 \%)$ e 2 por Mycobacterium $(1,6 \%)$ (Tabela 4).

As manifestaçóes relacionadas à açăo direta do virus no sistema nervoso foram diagnosticadas em 15 casos: 3 casos de mielopatia vacuolar associados a linfoma, criptococose e citomegalovirose; 2 casos de meningite de base; 10 com encefalite pelo HIV (6,4\%), 5 dos quais associados a infecçōes oportunistas. 


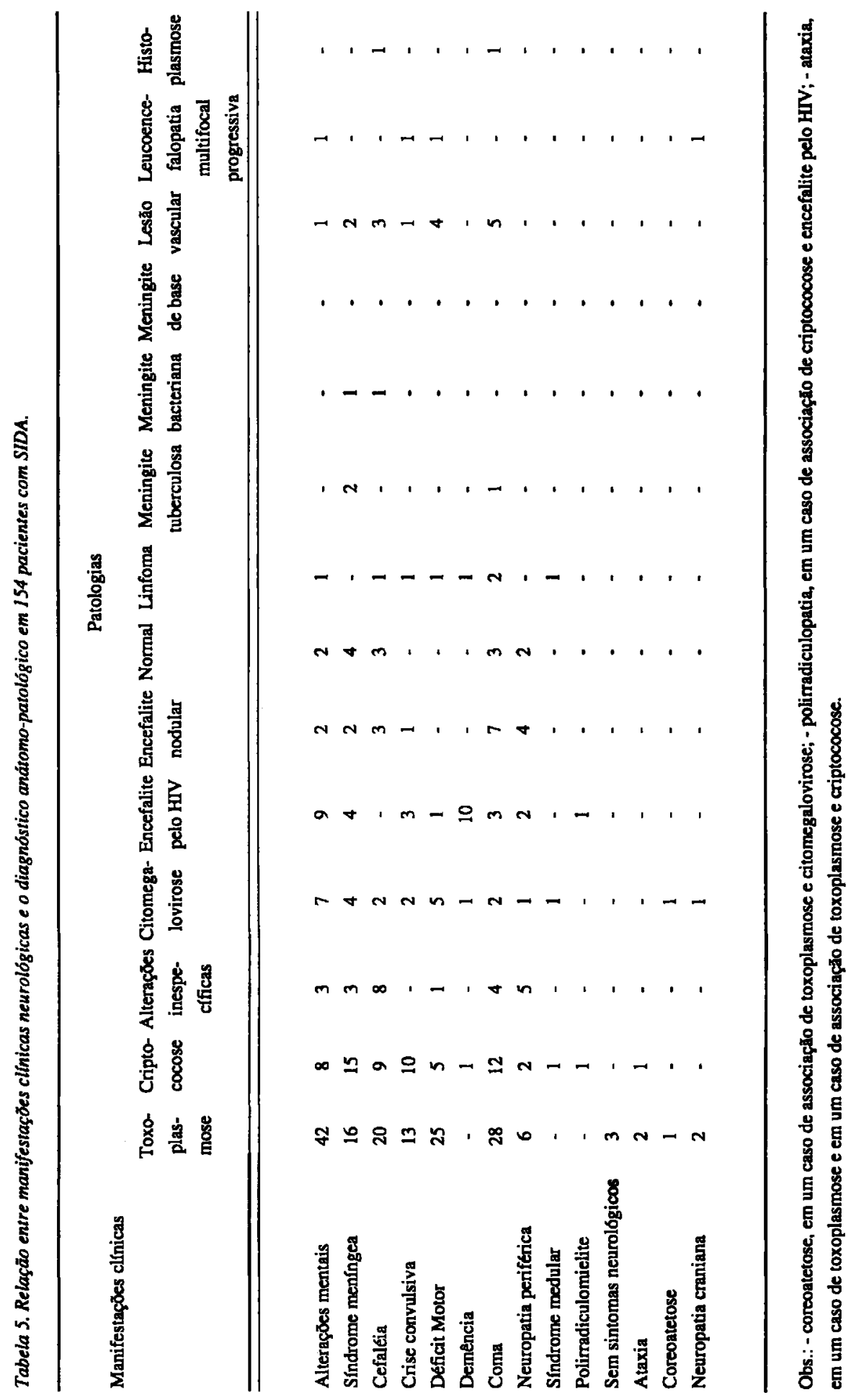


A leucoencefalopatia multifocal progressiva foi encontrada isoladamente em um caso e, em outro, associada a toxoplasmose e citomegalovirose.

Dados anátomo-clínicos - Neste estudo, após obtermos os dados clínicos e os anátomo-patológicos, estabelecemos a relaçăo entre esses resultados (Tabela 5).

Encontramos 1 caso de polirradiculomielite, em associaçăo de criptococose com encefalite pelo HIV. A ataxia causada por śndrome cerebelar foi encontrada em toxoplasmose, em 1 caso em associação com criptococose. Encontramos manifestação clínica de coreatetose em 1 caso de toxoplasmose associada a citomegalovirose.

Os nervos cranianos comprometidos foram o II (nervo óptico) em citomegalovirose, o VI (nervo abducente) em leucoencefalopatia multifocal progressiva, o III (nervo oculo-motor) em toxoplasmose e em toxoplasmose associada a criptococose e citomegalovirose.

\section{COMENTÁRIOS}

O aumento na incidência de SIDA vem determinando a elevação correspondente no número de casos com complicaçōes neurológicas ${ }^{13-15}$. Devido ao estado de imunossupressão, doenças graves concomitantes prejudicam a avaliação da prevalência das complicações neurológicas ${ }^{13,15,18}$. A faixa etária de comprometimento da doença é do adulto jovem e de meia idade; logo, ela atinge uma população em plena fase de atividade produtiva ${ }^{2}$. Nossos pacientes apresentaram faixa etária de comprometimento de 20 a 68 anos e a média de idade de $36,4 \%$ anos. Nosso estudo confirma dados da literatura quanto ao sexo, havendo prevalência do sexo masculino com 136 pacientes $(88,3 \%)$, enquanto 18 eram do sexo feminino $(11,7 \%)$.

Em 1985 foi descrito, pelo CDC, predomínio da transmissão por homens homossexuais e bissexuais em $75 \%$ dos casos $^{6}$. No Brasil, de 1980-1986, a distribuição quanto ao sexo masculino em individuos maiores de 15 anos foi de $46,5 \%$ para homossexuais e de $5 \%$ para heterossexuais. No período de 1991-1992 (até maio) a frequência na mesma faixa etária se manteve maior para homossexuais $(23,2 \%)$, mas aumentando para $20,4 \%$ em heterossexuais e $26,0 \%$ em usuários de droga ${ }^{23}$. No presente estudo predominou a transmissão por contacto sexual, registrada em 95 casos $(61,6 \%)$, sendo $70(45,5 \%)$ homossexuais e bissexuais. Este número é inferior ao relatado na literatura. Entretanto, se somarmos os pacientes homossexuais/droga e bissexuais/droga, que foram 16(10,3\%), alcançaremos o total de $86 \operatorname{casos}(55,8 \%)$, semelhante ao encontrado por Wendel e Russo ${ }^{17}$. Nesta casuística os casos de heterossexuais são 9 (5,8\%). Segundo Cortes e col. ${ }^{\mathrm{g}}$, no Brasil estamos mudando o modelo epidemiológico: há aumento de transmissão heterossexual e por drogas injetáveis, à semelhança do que ocorre nos países africanos. A próposito, deve-se lembrar dos casos em que o fator de risco é ignorado: em nossa casuística observamos 33 destes casos, sendo 27 do sexo masculino e 6 do feminino.

Quanto ao quadro clínico, em 1984 foram estudados 318 pacientes com SIDA na Universidade da Califómia em San Francisco, sendo identificados 124 (39\%) com sintomas neurológicos ${ }^{11}$. Na série de Koppel e col. ${ }^{9}$, esta ocorrência foi de 8,26\%. Vergara ${ }^{16}$ estudou 18 casos, 16 dos quais tinham lesão cerebral. Camara e col. ${ }^{5}$ em estudo de 113 casos encontraram predominfo de alterações mentais observadas em 33 casos $(29,2 \%)$. No presente estudo, de 154 pacientes necropsiados, 151 apresentaram sinais e sintomas neurologicos (98\%). Apenas 3 pacientes não apresentaram quadro neurologico mas tinham lesőes no SNC: 2 toxoplasmose e 1 citomegalovirose.

Devido à multiplicidade de sinais e sintomas neurológicos toma-se díficil fazer o diagnóstico, sendo o prognóstico muito reservado quando complicaçōes neurologicas sāo constatadas.

Com relação aos achados anátomo-patológicos, no estudo de Chimelli e Dumas ${ }^{7}$ é feita revisāo de 252 casos, tendo sido observadas lesð̃es de SNC em 91,3\%. Outros autores, como Petito ${ }^{12}$, Anders e col. ${ }^{1}$, Budka“ e Lang e col. ${ }^{10}$, fizeram estudo semelhante, também confirmando as lesões anátomopatologicas do SNC. Em nossa casuística o resultado foi de 94,1\%, pois dos 154 pacientes, 145 
tinham lesరes cerebrais. Encontramos tambem pacientes com máliplas lesoes do SNC, num total de $16(10,3 \%)$.

A incidencia de infeç̧óes oportunistas, para Chimelli e Dumas', foi de $65,4 \%$ sendo determinada por fungos, protozoários, bactérias $\mathrm{e}, \mathrm{em}$ menor número, por vírus. No estudo presente encontramos lesరes cerebrais por infecçбes oportunistas em $74 \%$ por: protozoários, fungos, bactérias e vírus. A frequência destes últimos foi maior que a encontrada por Chimelli e Dumas?.

Fizemos a correlaça anátomo-clínica com a preocupaça de fornecer informacoes úteis para o diagn6stico precoce e capazes de ajudar no estabelecimento de conduta teraplutica adequada. Esta $\epsilon$, portanto, uma tentativa de se conseguir tempo de vida maior para estes pacientes, que săo atingidos por múltiplos agentes agressores.

\section{REFERENCIAS}

1. Anders K, Steinsapir KD, Inverson DJ. Neuropathologic findings in the acquired immmodeficiency syndrome (AIDS). Clin Neuropathol 1986, 5:1-20.

2. Brasil. Ministério da Saude. Secretaria Nacional de Assistencia d Sate. Programa Necional de Doencas Sexualmente Transmissiveis/AIDS. Boletim Informativo, Braslie, 5(2), 1992.

3. Brasil. Ministerio da Sadde. Secretaria Nacional de Assitencia a Saude. Programa Nacional de Doenga Sexualmente Transmissfveie/AIDS. Boletim Epidemiológico, Brasilia, 5(11), 1991.

4. Budka H. Neuropathology of human immunodeficiency virus infection. Brin Puthol 1991, 1:163-175.

5. Camara VD, Chimelli L, Dumas M, Torres W, Moreira PF FP, Ribeiro M, Bazin AR. Manifeetations neurologiques du SIDA chez des malades: 113 necropsies dans 1 Hopital Universitaire Antonio Pedro. In Congres de Neurologie Tropical (Resumes). Limoges: Universite de Limoges, 1991, p 153.

6. Centers Disease Control. Classification system for human T-lymphocropic virus type III/lymphadenopathy associated virus infections. Morbidity and Mortality weekly Report. Washington, 1986, 35(20):334-339.

7. Chimelli L. Dumas M. Pathology of the central nervous system in patients infected with the human immunodeficiency virus (HIV): a report of 252 autopsy cases from Brazil. Niteroi: Hospital Universiturio Antonio Pedro, Departamento de Patologia, 8.d., 22p (no prelo).

8. Cortes E, De Tels R, Bulafia D, Moudgil T, Alam M, Bonecker C, Gonzaga A, Oyafuso L, Lonso M, Oite C, Hammersulak N, Capitini C, Slamon DJ, Ho DD. HIV-1, HIV-2 and HTLV-1. Infection in high-riek groups in Brazil. N Engl J Med 1989, 320:953-958.

9. Koppel BS, Wormer GP, Tuchman AJ. Central nervous system involvement in patients with scquired immunodeficiency syndrome (AIDS). Acta Neurol Scand 1985, 71:337-353.

10. Lang W, Mikloss J, Dernaz JP. Neuropathology of the acquired immunodeficiency syndrome (AIDS): a report of 135 consecutive autopsy cases from Switzerland. Acta Neuropethol (Beri) 77:379-390.

11. Levy RM, Bredesen DE, Rosenblum ML. Neurological manifestations of the acopired immunodeficiency syndrome (AIDS): experience at UCFS and review of the literature. J Neurosurg 1985, 62:475-495.

12. Petito CK. Review of central nervous system pathology in human immunodeficiency virus infection. Ann Neurol 1988 (Suppl 1), 23:54-S7.

13. Rio de Janeiro. Secretaria da Saude. Superintencia de Saude Coletiva. Coondenadoria de Vigillncia. Divisllo de Controle de DST/AIDS, fev/mar. 1992.

14. Rio de Janeiro. Secretaria de Saúde. AIDS no Estado do Rio de Janeiro - 1991/1992. Bol epidemiológico sobre AIDS, Rio de Janeiro, 6-8, dez 91/jan 92.

15. Rio de Janeiro. Secretaria de Estado de Saude. Divisto de DST/AIDS. Manual de vigillancia epidemiologica da AIDS, 1989.

16. Vergara TRC. Manifestaçoes neurologicas da síndrome de imunodeficiencia adquirida. Arq Bras Med 1986, 60:173-190.

17. Wendel S Neto, Russo C. Sindrome de imunodeficiencia adquirida (AIDS): epidemiologia, fisiopatologia, quadro clínico, prevençio e tratamento. Consenso Med 1985, 1:29-35.

18. World Health Organization. Report of the consultation of the neuropsychiatric aspects of HIV infection. Geneva 1988, 14-17. 